\title{
Estimating rates and sources of sea level change during past warm periods
}

\section{P A L S E A}

\author{
Glenn Milne', A. Carlson², A. Dutton ${ }^{3}$, A. Long ${ }^{4}$ and O. Rybak ${ }^{5,6}$
}

PALSEA2 Workshop, Rome, Italy, 21-25 October 2013

The greatest uncertainty in projecting future sea level rise is that associated with the response of Earth's ice sheets to climate change. The primary aim of the PALeo constraints on SEA level rise (PALSEA) Working Group is to reduce this uncertainty using geological information of past ice sheet and sea level variability with a focus on past warm periods when the configuration of ice on Earth was similar to today. Due to the success of this working group during its first phase, it has been approved for a second phase (PALSEA2) and the meeting reported on here is the first in this second phase.

Estimating rates and sources of sea level change during the last interglaciation (LIG; ca. 130-115 ka ago) was the dominant part of the meeting. Recently, significant progress has been made in improving estimates of the minimum volume of land ice during this period with a range of $5.5-9 \mathrm{~m}$ currently documented as the most likely (Kopp et al. 2009; Dutton and Lambeck 2012). A number of observations suggest more than one sea level high stand during this period. Reconstructions based on a range of sea level indicators from different regions were presented at the workshop and all support temporal variability within the LIG with millennial average rates ranging from the order of decimeters per century to meters per century. The discrepancy in these values relates primarily to limitations in height and time precision of the reconstruction methods used. Therefore, an important target for the community is the production of more precise sea level records for this period.

Interpreting both the volume and variability of reconstructed LIG sea levels requires consideration of near-field constraints on ice extent for both the Greenland and Antarctic ice sheets as well as models of their evolution across the LIG. While there remains considerable variation in estimates of the minimum volume extent of the Greenland ice sheet during the LIG, most recent studies indicate relatively stable rates of mass loss with a maximum sea level contribution in the range $0.5-3.5 \mathrm{~m}$ for this period (Fig. 1), consistent with observations (e.g. Colville et al. 2011; NEEM 2013). There is much less data control on Antarctic ice sheet changes, making this an important research goal in the coming years. Modeling results presented at the meeting suggest that a relatively large and rapid retreat of the Antarctic ice sheets first requires significant warming of the Southern Ocean in order to melt ice shelves.

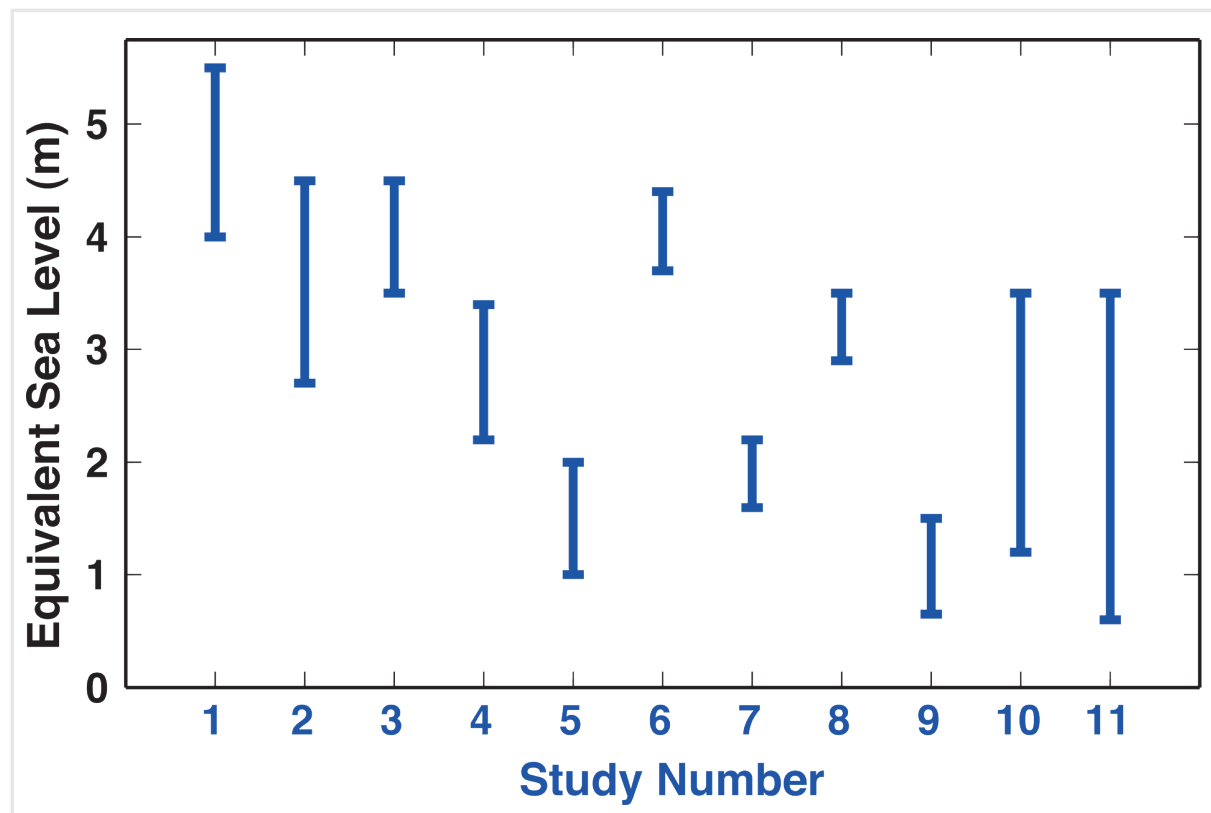

Figure 1: Estimates of the contribution of the Greenland ice sheet to global mean sea level during the Last Interglacial. The studies numbered in publication order along the $\mathrm{x}$-axis are: (1) Cuffey and Marshall (2000); (2) Tarasov and Peltier (2003; most likely range shown); (3) L'homme et al. (2005; most likely range shown); (4) OttoBliesner et al. (2006); (5) Oerlemans et al. (2006); (6) Robinson et al. (2011; most likely range shown); (7) Colville et al. (2011); (8) Born and Nisancioglu (2012); (9) Quiquet et al. (2012); (10) Helsen et al. (2013); (11) Stone et al. (2013). Only studies that provided a range of values are shown here.

An issue common to all time periods discussed at the workshop was the challenge of estimating global mean sea level (to determine past ice volume) from a limited set of site specific relative sea level data. Reconstructions of the latter for the middle Pliocene (ca. 3.3-2.9 Ma) can be significantly affected by both glacial isostatic adjustment and dynamic topography driven by internal mantle buoyancy (e.g. Rowley et al. 2013). Uncertainty in model estimates of the contribution of these processes to Pliocene sea levels is a primary limitation in estimating ice volume within a reasonable precision ( $10 \mathrm{~m})$. A similar problem relates to the interpretation of high-resolution sea-level records for the past few centuries to millennia. As more records become available, it is becoming clear that there is a large overprint associated with ocean dynamical changes.

This has important implications for using these records to calibrate semi-empirical models of global mean sea level (e.g. Kemp et al. 2011).

Through future workshops and conference sessions, the PALSEA2 Working Group will stimulate and encourage researchers to address the data and knowledge gaps highlighted above.

\section{AFFILIATIONS}

'Department of Earth Sciences, University of Ottawa, Canada

${ }^{2}$ College of Oceanic and Atmospheric Sciences, Oregon State University, Corvallis, USA

${ }^{3}$ Department of Geological Sciences, University of Florida, Gainsville, USA

${ }^{4}$ Department of Geography, Durham University, UK ${ }^{5}$ Department of Geography, Free University of Brussels, Belgium

Institute of Natural and Technical Systems of the Russian Academy of Sciences, Sochi, Russia

\section{CONTACT}

Glenn Milne: gamilne@uottawa.ca

REFERENCES

Colville EJ et al. (2011) Science 333: 620-623

Dutton A, Lambeck K (2012) Science 337: 216-219 Kemp AC et al. (2011) PNAS 108: 11017-11022 Kopp RE et al. (2009) Nature 462: 863-867

NEEM community members (2013) Nature 493: 489-494 